\title{
Aplikasi Himpunan Kritis Pada Pelabelan Graf Caterpillar Teratur $C_{4_{n}}$
}

\author{
Triyani, Siti Rahmah Nurshiami, Mutia Nur Estri \\ Program Studi Matematika, Jurusan MIPA \\ Fakultas Sains dan Teknik \\ Universitas Jenderal Soedirman \\ Jl. Dr. Soeparno Karangwangkal Purwokerto \\ trianisr@yahoo.com.au,nurshiami@yahoo.co.id,mutia_ne_yusuf@yahoo.com
}

\begin{abstract}
ABSTRAK
Graf yang dapat dilabeli dengan pelabelan Total Super Sisi Ajaib (TSSA) disebut graf super sisi ajaib. Graf Caterpillar Teratur $C_{4_{n}}$ merupakan graf super sisi ajaib. Label titik dan label sisi pada Graf Super Sisi Ajaib dapat digunakan untuk menentukan himpunan kritis pada pelabelan graf. Himpunan kritis ini dapat diimplementasikan ke dalam Secret Sharing Scheme (SSS). Penelitian ini membahas aplikasi himpunan kritis pada graf Caterpillar Teratur $C_{4_{n}}$ untuk $n=2$ dalam sistem informasi akademik.
\end{abstract}

Kata Kunci : pelabelan total super sisi ajaib, himpunan kritis.

\section{ABSTRACT}

A super edge magic graph is a graph that can be labeled with edge magic total (EMT) labeling. Caterpillar Regular graph $\boldsymbol{C}_{\mathbf{4}_{n}}$ is a super edge magic graph. Label for vertices and edge on super edge magic graph can be used to determine critical set of labelling graph. The critical set can be implemented to Secret Sharing Scheme (SSS). The results of this study show that the critical set of Caterpillar Regular graph $\boldsymbol{C}_{\mathbf{4}_{n}}$ for $n=2$ can be applied to academic information system.

Keywords: super edge magic labeling, critical set.

\section{Pendahuluan}

Pelabelan total sisi ajaib pada graf $G$ dengan $n$ titik dan $m$ sisi adalah fungsi bijektif yang memetakan setiap titik dan sisi dari graf $G$ ke bilangan bulat positif $\{1,2, \ldots, n+m\}$ sedemikian sehingga jumlah label titik dan label sisi yang bersisian dengan kedua titik tersebut adalah konstanta $k$. Nilai $k$ ini selanjutnya disebut konstanta ajaib untuk graf $G$. Pelabelan graf dikatakan pelabelan total super sisi ajaib apabila label untuk titik-titik pada graf $G$ adalah bilangan terurut dari $1,2, \ldots, n$. Graf yang dapat dilabeli dengan pelabelan Total Super Sisi Ajaib (TSSA) disebut graf super sisi ajaib. Sebuah himpunan kritis pada pelabelan graf $G$ adalah subhimpunan label dan posisi label tersebut yang apabila dilengkapi akan menghasilkan pelabelan tersebut secara tunggal (Imron, dkk. [4]).

Masalah menentukan himpunan kritis dari suatu pelabelan graf merupakan masalah yang tidak mudah. Hal ini dikarenakan kemungkinan dari subhimpunan label pada graf sangat banyak. Kemudian dari masing-masing 
subhimpunan tersebut dicari subhimpunan label yang membangun satusatunya pelabelan dari graf (Baskoro, dkk. [1]). Gambar 1(a) merupakan gambar graf lintasan $\left(P_{n}\right)$ dengan 3 buah titik atau $P_{3}$, dan Gambar 1(b) merupakan salah satu posisi label pada graf lintasan $P_{3}$. Misalkan $f$ dan $g$ fungsi yang memetakan titik dan sisi pada graf lintasan $P_{3}$ ke bilangan bulat $\{1,2, \ldots, 5\}$ seperti pada Gambar 2. Dalam hal ini $f=\{(1,1),(2,5),(3,3),(4,4),(5,2)\}$ dan $g=\{(1,2),(2,3),(3,5),(4,4),(5,1)\}$, bilangan bulat pertama menyatakan posisi label pada graf $P_{3}$, sedangkan bilangan bulat kedua menyatakan label titik atau label sisi pada graf $P_{3}$. Graf lintasan $P_{3}$ pada Gambar 2(a) merupakan graf total super sisi ajaib dengan konstanta ajaib $k=1+5+3=3+4+2=9$, sedangkan graf lintasan $P_{3}$ pada Gambar 2(b) merupakan graf total sisi ajaib dengan konstanta ajaib $k=2+3+5=5+4+1=10$.

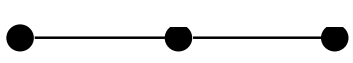

(a)

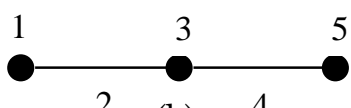

(b)

Gambar 1 Graf lintasan $P_{3}$ dan posisi label untuk graf lintasan $P_{3}$
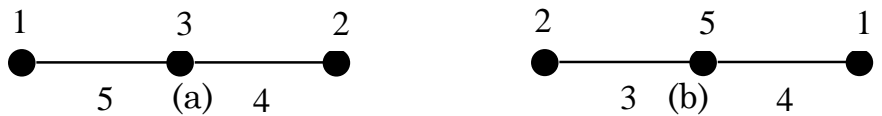

Gambar 2 Pelabelan total sisi ajaib pada Graf $P_{3}$

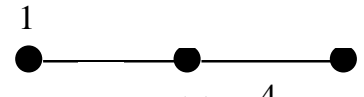

(a)

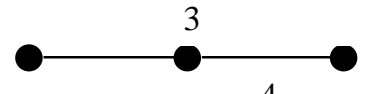

(b)

Gambar 3 Himpunan Kritis dan bukan himpunan kritis pada Graf $P_{3}$

Himpunan $\{(1,1),(4,4)\}$ pada Gambar 3(a) merupakan subhimpunan dari $f$. Supaya himpunan tersebut menjadi pelabelan total sisi ajaib, titik dan sisi pada graf tersebut yang belum diberi label harus dilengkapi. Label yang belum digunakan adalah label 2, label 3, dan label 5. Apabila label 2 ditempatkan pada posisi label ke-2, label 3 ditempatkan pada posisi label ke-3, dan label 5 ditempatkan pada posisi label ke-5 sehingga tidak diperoleh konstata ajaib $k$, karena $1+2+3 \neq 3+4+5$. Namun, apabila label 2 ditempatkan pada posisi label ke-5, label 3 ditempatkan pada posisi label ke-3, dan label 5 ditempatkan pada posisi label ke-2 sehingga diperoleh konstata ajaib $k$, karena $1+5+3=9=3+4+2$. Hal ini berarti apabila himpunan $\{(1,1),(4,4)\}$ dilengkapi dengan memberikan label titik dan label sisi yang belum diberi label pada Gambar 3(a), sehingga membentuk satu-satunya pelabelan total sisi ajaib dengan himpunan $\{(1,1),(2,5),(3,3),(4,4),(5,2)\}=f$. Akibatnya, himpunan $\{(1,1),(4,4)\}$ merupakan 
salah satu himpunan kritis pada pelabelan total sisi ajaib graf $P_{3}$ dengan fungsi f. Himpunan $\{(3,3),(4,4)\}$ pada Gambar 3(b) merupakan subhimpunan dari $f$, tetapi bukan himpunan kritis pada pelabelan total sisi ajaib graf $P_{3}$. Hal ini dikarenakan apabila label 5 ditempatkan pada posisi label ke-1, label 1 ditempatkan pada posisi label ke-2, dan label 2 ditempatkan pada posisi label ke-5, sehingga diperoleh konstanta ajaib $k=5+1+3=9=3+4+2$. Dengan kata lain terdapat pelabelan total sisi ajaib lain selain $f$ yaitu $h=\{(1,5),(2,1),(3,3),(4,4),(5,2)\}$ yang memuat himpunan $\{(3,3),(4,4)\}$.

Himpunan kritis pada pelabelan graf dapat diaplikasikan ke dalam masalah Secret Sharing Scheme(SSS). SSS merupakan suatu metode untuk membagi (share) rahasia $S$ kepada sejumlah partisipan $R=\left\{R_{1}, R_{2}, R_{3}, \ldots, R_{n}\right\}$ sedemikian sehingga hanya partisipan dalam himpunan $A$ yang diberi wewenang saja $(A \subseteq R)$ yang dapat merekonstruksi rahasia $S$ dengan cara mengumpulkan semua informasi parsial dari masing-masing anggota di $A$. Dengan demikian, untuk setiap $B \subseteq R$ yang tidak punya wewenang, mereka tidak akan dapat merekonstruksi $S$. Kunci rahasia $\mathrm{S}$ dipilih oleh Dealer $D$, dan diasumsikan $D \notin$ $R$ (Baskoro dkk., [1]).

Kajian tentang himpunan kritis pada pelabelan total sisi ajaib yang telah dilakukan antara lain : himpunan kritis pada pelabelan graf khususnya graf bintang dan graf bintang ganda (Baskoro [2]), himpunan kritis pada pelabelan graf Caterpillar (Imron dkk., [4]), himpunan kritis pada pelabelan graf Banana Tree (Hussain dkk.,[3]). Penelitian ini membahas himpunan kritis pada pelabelan graf Caterpillar Teratur $C_{4_{n}}$ untuk $n=2$, dan mengimplementasikan ke dalam skema pembagian rahasia khususnya dalam sistem pengamanan informasi akademik.

\section{Metode Penelitian}

Metode dalam penelitian ini adalah ekperimental dengan tahapan sebagai berikut. Tahap pertama adalah kajian literatur, yaitu penelusuran pustaka tentang himpunan kritis dari pelabelan TSSA pada beberapa kelas graf. Tahap kedua mengidentifikasi dan merumuskan masalah. Kegiatan yang dilakukan pada tahap ini adalah menggali masalah riil dan mencoba menyelesaikannya dengan topik yang digunakan dalam penelitian ini yaitu pelabelan TSSA. Tahap ketiga adalah penentuan himpunan kritis dari pelabelan TSSA pada graf Caterpillar Teratur $C_{4_{n}}$. Pada tahapan ini dilakukan investigasi himpunan kritis dari hasil formula pelabelan dengan cara mengenumerasi semua kemungkinan pelabelan TSSA pada graf Caterpillar Teratur $C_{4_{n}}$. Tahap selanjutnya yaitu tahap keempat adalah mengimplementasikan himpunan kritis ke dalam masalah SSS. Pada tahapan ini hasil yang telah diperoleh pada tahap ke-3 diimplementasikan ke dalam masalah Secret Sharing Scheme, khususnya dalam sistem pengamanan informasi akademik di dunia pendidikan. 


\section{Hasil dan Pembahasan}

Graf Caterpillar Teratur $C_{4_{n}}$ seperti pada Gambar 4 mempunyai titik sebanyak $5 n$ yaitu titik $w_{1}, w_{2}, \ldots, w_{2 n}, x_{1}, x_{2}, \ldots, x_{2 n}, z_{1}, z_{2}, \ldots, z_{n}$ dan mempunyai sisi sebanyak $5 n-1$, yaitu $w_{i} z_{j}, x_{i} z_{j}, z_{k} z_{k+1}$ dengan $1 \leq i \leq 2 n, 1 \leq j \leq n$, $1 \leq k \leq n-1$. Graf Caterpillar Teratur merupakan graf Super Sisi Ajaib, yaitu graf yang dapat dilabeli dengan pelabelan TSSA.

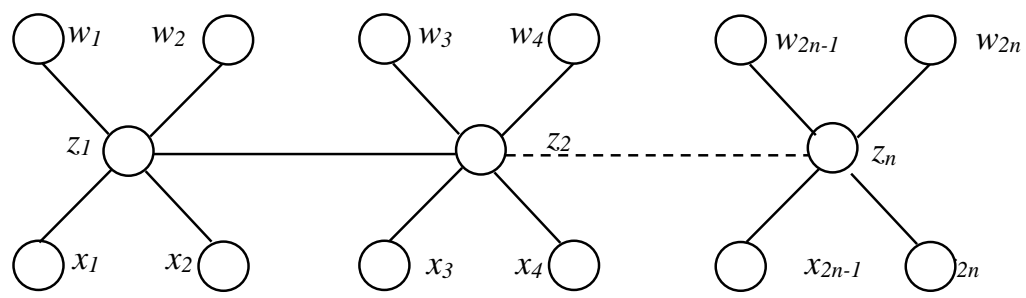

Gambar 4 Graf Caterpillar Teratur $C_{4_{n}}$

\section{Himpunan Kritis pada Pelabelan Graf Caterpillar Teratur $C_{4_{2}}$.}

Graf Caterpillar Teratur $C_{4_{2}}$ mempunyai 10 buah titik dan 9 buah sisi. Graf pada Gambar 5(a) merupakan posisi pemberian label pada graf $C_{4_{2}}$, sedangkan graf pada Gambar 5(b) merupakan contoh pelabelan TSSA pada graf $C_{4_{2}}$. Himpunan $\lambda$ berikut menyatakan pelabelan TSSA pada $C_{4_{2}}$ seperti Gambar $5(\mathrm{~b}), \lambda\left(C_{4_{2}}\right)=\{(1,6),(2,19),(3,1),(4,17),(5,3),(6,18),(7,2),(8,16),(9,4),(10,15)$, $(11,5),(12,14),(13,7),(14,12),(15,9),(16,13),(17,8),(18,11),(19,10)\}$ dengan konstanta ajaib $k=1+19+6=6+18+2=\ldots=5+11+10=26$.

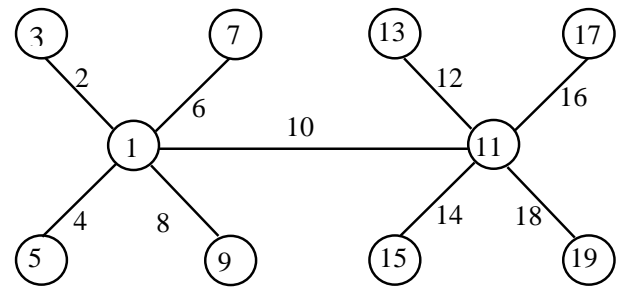

(a)

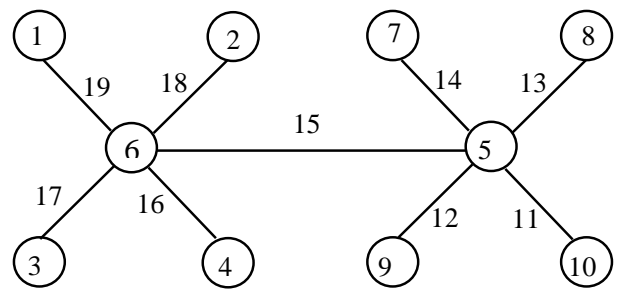

(b)

Gambar 5 Posisi label dan pelabelan TSSA pada graf $C_{4_{2}}$

Himpunan kritis pada pelabelan TSSA $\lambda$ dari graf Caterpillar Teratur $C_{4_{2}}$ didefinisikan sebagai, $Q_{\lambda}\left(C_{4_{2}}\right)=\{(a, b) \mid a, b \in\{1,2, \ldots, 19\}\}$ dengan $(a, b)$ adalah pasangan terurut yang menyatakan label $b$ pada posisi $a$, sedemikian sehingga $Q_{\lambda}\left(C_{4_{2}}\right)$ harus memenuhi : 
1) $\quad \lambda$ adalah satu-satunya pelabelan pada $C_{4_{2}}$ dengan label $b$ pada posisi a yang dapat direkonstruksi dari $Q_{\lambda}\left(C_{4_{2}}\right)$.

2) Setiap sub himpunan dari $Q_{\lambda}\left(C_{4_{2}}\right)$ tidak memenuhi sifat (1).

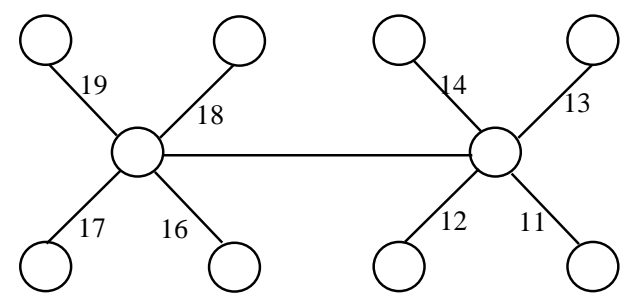

Gambar 6 Bukan himpunan kritis dari $C_{4_{2}}$

Himpunan $Q_{\lambda}\left(C_{4_{2}}\right)=\{(2,19),(4,17),(6,18),(8,16),(12,14),(14,12),(16,13)$, $(18,11)\}$ pada Gambar 6 bukan merupakan himpunan kritis dalam pelabelan TSSA pada graf $C_{4_{2}}$, karena himpunan tersebut tidak memenuhi syarat (1). Pelabelan TSSA lain yang dapat direkonstruksi adalah $\lambda_{1}\left(C_{4_{2}}\right)=\{(1,1),(2,19),(3,6),(4,17),(5,8),(6,18),(7,7),(8,16),(9,9),(10,15)$, $(11,10),(12,14),(13,2),(14,12),(15,4),(16,13),(17,3),(18,11),(19,5)\}$.

Beberapa himpunan kritis pelabelan $\lambda$ pada graf Caterpillar Teratur $C_{4_{2}}$ adalah $Q_{1_{\lambda}}\left(C_{4_{2}}\right)=\{(\mathbf{3}, \mathbf{1}),(\mathbf{7}, \mathbf{2}),(\mathbf{1 3}, \mathbf{7}),(\mathbf{1 7}, \mathbf{8}),(5,3),(9,4),(15,9),(19,10)\}$ $Q_{2_{\lambda}}\left(C_{4_{2}}\right)=\{(\mathbf{3}, \mathbf{1}),(\mathbf{7}, \mathbf{2}),(\mathbf{1 3}, \mathbf{7}),(\mathbf{1 7}, 8),(4,17),(8,16),(14,12),(18,11)\}$ $Q_{3_{\lambda}}\left(C_{4_{2}}\right)=\{(\mathbf{3}, \mathbf{1}),(\mathbf{7}, \mathbf{2}),(\mathbf{1 3}, \mathbf{7}),(\mathbf{1 7}, \mathbf{8}),(4,17),(8,16),(14,2),(19,10)\}$.

Tanpa mengurangi keumuman, dapat ditunjukkan bahwa himpunan $Q_{1_{\lambda}}\left(C_{4_{2}}\right)$ dapat digambarkan seperti Gambar 7 memenuhi syarat (1) dan (2).

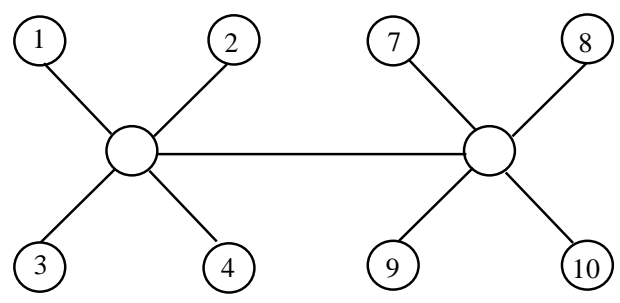

Gambar 7 Himpunan kritis $Q_{1_{\lambda}}\left(C_{4_{2}}\right)$

Label untuk titik dan sisi yang belum digunakan adalah label 5, 6, 11, $12,13,14,15,16,17,18$, dan 19. Untuk memudahkan melengkapi menjadi pelabelan total sisi, posisi label ke-1 dan ke-11 harus diberi label terlebih dahulu. Gunakan label terkecil yaitu label 5 dan 6 masing-masing di posisi label ke-1 dan ke-11, sehingga jumlah label untuk dua buah titik yang bertetangga 
berturut-turut adalah $6,7,8,9,11,13,14,15$, dan 16 . Akibatnya apabila label $11,12,13,14,15,16,17,18$, dan 19 ditempatkan pada setiap sisi dari graf $C_{4_{2}}$ maka tidak terdapat konstanta $k$, sehingga pelabelannya tidak ajaib. Namun, apabila label 6 dan 5 masing-masing di posisi label ke-1 dan ke-11, sehingga jumlah label untuk dua buah titik yang bertetangga berturut-turut menjadi 7 , $8,9,10,11,12,13,14$, dan 15. Selanjutnya label yang belum digunakan diurutkan dari yang terbesar yaitu 19, 18, 17, 16, 15, 14, 13, 12, 11 dan ditempatkan berturut-turut pada sisi yang berinsiden dengan dua buah titik yang mempunyai jumlah label terkecil sampai jumlah label terbesar. Akibatnya terdapat konstanta ajaib $k=7+19=8+18=\ldots=15+11=26$. Hal ini berarti apabila himpunan $Q_{1_{\lambda}}\left(C_{4_{2}}\right)$ dilengkapi dengan memberikan label titik dan label sisi yang belum diberi label, sehingga membentuk satu-satunya pelabelan total sisi ajaib pada $C_{4_{2}}$ yaitu pelabelan $\lambda\left(C_{4_{2}}\right)$. Jadi memenuhi syarat (1).

Ambil $P=\{(3,1),(7,2),(13,7),(9,4),(15,9),(19,10)\}$ yang merupakan sub himpunan dari $Q_{1_{i}}\left(C_{4_{2}}\right)$. Apabila himpunan $P$ dilengkapi label titik dan sisinya sehingga terdapat pelabelan

$$
\begin{aligned}
& \lambda_{2}\left(C_{4_{2}}\right)=\{(1,6),(2,19),(3,1),(4,3),(5,17),(6,18),(7,2),(8,16),(9,4),(10,15),(11,5),(12,14), \\
&(13,7),(14,12),(15,9),(16,13),(17,8),(18,11),(19,10)\} . \\
& \lambda_{3}\left(C_{4_{2}}\right)=\{(1,6),(2,19),(3,1),(4,3),(5,17),(6,18),(7,2),(8,16),(9,4),(10,15),(11,5),(12,14), \\
&(13,7),(14,12),(15,9),(16,8),(17,13),(18,11),(19,10)\} . \\
& \lambda_{4}\left(C_{4_{2}}\right)=\{(1,6),(2,19),(3,1),(4,17),(5,3),(6,18),(7,2),(8,16),(9,4),(10,15),(11,5),(12,14), \\
&(13,7),(14,12),(15,9),(16,13),(17,8),(18,11),(19,10)\} .
\end{aligned}
$$

Hal ini berarti sub himpunan dari $Q_{1_{\lambda}}\left(C_{4_{2}}\right)$ tidak merekonstruksi satu-satunya pelabelan, sehingga memenuhi syarat (2).

\section{Implementasi Himpunan Kritis Pelabelan TSSA pada Graf $C_{4_{2}}$ dalam Secret Sharing Scheme}

Masalah SSS pada pelabelan graf telah dilakukan oleh Imron dkk., [4]. Himpunan kritis pada graf Caterpillar diimplementasikan ke dalam bentuk pembagian password antara supervisor dengan kasir di suatu supermarket. Pada penelitian ini himpunan kritis dari pelabelan graf diimplementasikan ke dalam sistem pengamanan informasi akademik di dunia pendidikan.

Fakultas Sains dan Teknik UNSOED terdiri dari tiga jurusan, yaitu Jurusan MIPA, Jurusan Teknik, dan Jurusan Perikanan dan Kelautan. Masing-masing jurusan mempunyai bagian administrasi kependidikan, yang salah satu tugasnya adalah mengolah transkrip akademik mahasiswa melalui Sistem Informasi Akademik (SIA). Tiap jurusan menugaskan salah satu staf administrasinya untuk menjalankan tugas tersebut. Staf administrasi tersebut mendapatkan akses khusus untuk menambah atau mengubah nilai. Untuk 
dapat mengakses sistem, staf tersebut diberi password. Kebenaran transkrip nilai menjadi tanggung jawab Pembantu Dekan I yang juga mempunyai akses khusus ke SIA.

Selama ini penambahan dan perubahan nilai dapat dilakukan oleh staf administrasi tanpa sepengetahuan Pembantu Dekan I, karena staf administrasi dapat mengakses dengan menggunakan password sendiri tanpa ada kaitannya dengan password Pembantu Dekan I. Hal tersebut bisa menyebabkan adanya kesalahan yang mungkin tidak terdeteksi oleh Pembantu Dekan I. Untuk memperkecil kesalahan tersebut dapat menggunakan Secret Sharing Scheme (SSS), dimana staf administrasi tidak akan bisa langsung mengakses sistem sebelum Pembantu Dekan I memasukkan password ke dalam sistem. Pada SSS, barisan password dibagi menjadi bagian-bagian tertentu dan memberikannya kepada sekelompok orang yang berhak.

Himpunan Kritis dari pelabelan TSSA pada graf Caterpillar Teratur $C_{4_{2}}$ dapat diimplementasikan dalam Secret Sharing Scheme di Bidang pendidikan. Jika seorang staf ingin mengubah suatu nilai dari mata kuliah tertentu, maka perubahan nilai ini harus diketahui oleh Pembantu Dekan I. Pembantu Dekan I akan memasukan passwordnya dan staf akademik melengkapi dengan memasukkan passwordnya. Hal ini menunjukkan bahwa Pembantu Dekan I lebih berkuasa dari pada staf dan Pembantu Dekan I bertanggung jawab dalam perubahan nilai suatu mata kuliah. Irisan dari himpunan kritis $Q_{1_{\lambda}}\left(C_{4_{2}}\right)$, $Q_{2_{\lambda}}\left(C_{4_{2}}\right)$ dan $Q_{3_{\lambda}}\left(C_{4_{2}}\right)$, yaitu

$$
S=\bigcap_{i=1}^{3} Q_{i_{\lambda}}\left(C_{4_{2}}\right)=\{(3,1),(7,2),(13,7),(17,8)\}
$$

merupakan password untuk Pembantu Dekan I. Sedangkan password untuk staf akademik Jurusan MIPA, Teknik, dan Perikanan Kelautan berturut-turut adalah

$$
\begin{aligned}
& P_{1}=\{(5,3),(9,4),(15,9),(19,10)\} \\
& P_{2}=\{(4,17),(8,16),(14,12),(18,11)\} \\
& P_{3}=\{(4,17),(8,16),(14,2),(19,10)\} .
\end{aligned}
$$

Apabila seorang staf administrasi dari jurusan MIPA dan Pembantu Dekan I ingin mengetahui apakah pembagian secret tersebut benar atau tidak, maka staf dan Pembantu Dekan I harus memasukkan password tersebut secara bersamasama. Sebagai contoh, password untuk staf administrasi jurusan MIPA adalah $P_{1}=\{(5,3),(9,4),(15,9),(19,10)\}$, sedangkan password untuk Pembantu Dekan I adalah $S=\{(3,1),(7,2),(13,7),(17,8)\}$. Apabila passwordnya digabungkan maka akan menjadi 


$$
\begin{aligned}
P_{1} \cup S & =\{(5,3),(9,4),(15,9),(19,10)\} \cup\{(3,1),(7,2),(13,7),(17,8)\} \\
& =\{(3,1),(7,2),(13,7),(17,8),(5,3),(9,4),(15,9),(19,10)\} \\
& =Q_{1_{\lambda}} .
\end{aligned}
$$

Jadi himpunan kritis $Q_{1_{\lambda}}\left(C_{4_{2}}\right)$ merupakan secret untuk jurusan MIPA.

\section{Simpulan}

Kesimpulan yang dapat diperoleh dari penelitian ini yaitu himpunan kritis dari pelabelan TSSA pada graf Caterpillar Teratur $C_{4_{2}}$ dapat diimplementasikan ke dalam masalah SSS. Khususnya masalah sistem pengamanan informasi akademik.

\section{Daftar Pustaka}

1. Baskoro, E. T., Rinovia S., dan Mariskha T. A. 2004. Secret Sharing Scheme Based On Magic Labeling. Department of Mathematics. ITB Bandung.

2. Baskoro, E. T., 2005. Critical sets in Edge-Magic Total Labellings. J. Combin. Math. Combin. Comput. 55, pp 33 - 42.

3. Hussain, M., Baskoro, E. T., Slamin. 2009. On Super Edge-Magic Total Labeling Of Banana Trees. Utilitas Math. 79, pp 243-251. .

4. Imron C, Setiyono B, Simanjutak R, Baskoto E. T., 2008. Critical Set of Caterpillar Graph for Secret Sharing Scheme, J. Combin. Math. Combin. Comput. 65, pp 121-126. 